ALRNATR

Paper ID \#7248

\title{
A Documentary Project in a Civil Engineering Course
}

Dr. Seamus F Freyne P.E., Mississippi State University

On the civil engineering faculty at Mississippi State University, Dr. Seamus Freyne teaches structures courses and his research interests include engineering education. 


\section{A DOCUMENTARY PROJECT IN A CIVIL ENGINEERING COURSE}

\section{Overview}

An innovative documentary project in an undergraduate civil engineering course at Mississippi State University was found to provide students with a unique perspective and a chance to demonstrate creativity and teamwork skills.

Teams of students in two steel structures courses produced short documentaries approximately ten minutes in length. The documentaries were made to be educational in nature and also enjoyable to watch, much like shows on the Discovery, History, and National Geographic channels.

As a subject, each team chose to profile a different aspect of steel structures. Company profiles included interviews with several individuals within a company about the steel structures business, what services they provide, significant projects, and new challenges and developments. Project profiles included interviews with representatives from several companies about design and construction, types of structural members and connections, schedule, and cost.

Students made contact with the companies and professionals they wanted to include in the documentaries. Most everyone contacted was accessible and helpful though students sometimes needed to work within constraints. To alleviate privacy concerns, the documentaries were not made available beyond the class.

Students went on location to see steel structures and interview professionals of all specialties and levels. Students did preliminary research to prepare some questions ahead of the interviews and asked additional questions as the conversations unfolded. Students chose to work both behind the camera and in front of the camera, and they recorded at least thirty minutes of material, three times as much as they would eventually use. The documentaries exclusively contained original content.

Students edited the documentaries with programs such as Apple iMovie where they organized the information they collected and told a story as concisely as possible. They included both interviews and narrative, identified all speakers and scenes, and added voice, text, and music as they wished. Students provided faculty with the final products as well as transcripts of the documentaries. The documentaries were showed in class and graded on the basis of quality of content and style of presentation. 
A total of 69 students in steel structures courses in the 2010 and 2012 fall terms made documentaries. On a questionnaire, students favorably assessed this project against more traditional team activities like reports and presentations in terms of interest and educational value. Students generally appreciated the variety the project gave them from the weekly routine of textbook problem sets, and they commented extensively on likes and dislikes. In addition to the educational experience, anecdotal evidence suggests that students made job contacts at several companies and also prompted the loyalty and appreciation of alumni who were subjects of the documentaries. This project is easily implementable into almost any undergraduate civil engineering course and meets several ABET outcomes.

\section{Documentaries as Educational Tools}

Old curriculums must be updated with more dynamic and flexible teaching styles to accommodate the way students want to learn. ${ }^{1}$ A documentary project is a potentially useful educational tool that can complement traditional coursework such as textbook problem sets. The main contribution to student achievement is improvement of communication skills.

The absence of much literature on student documentaries is evidence of the novelty of this exercise. Previously, at two universities, undergraduates in geotechnical laboratory courses made documentaries of experimental procedures, and the activity was found to enhance student enjoyment and engagement. These documentaries, each a maximum of three minutes in length, were made available to students at both universities. The efforts were graded mainly on technical content and less on cinematic appeal. ${ }^{2}$

The idea of student documentaries has been proposed at the ASCE Excellence in Civil Engineering Education (ExCEEd) practicum. Many civil engineering students lack the communication skills they will need to be successful professionally. Said Andrew Herrmann, 2011/2012 ASCE president: "You could design the best bridge in the world, but if you can't communicate the details to other engineers, the public, or officials, what good is it?",3

\section{More Details of the Project}

Teams were composed of three to five students, and both classes had eight teams. Teams were selected randomly so students were likely to work with peers they might not initially know well.

Students made contact with professionals at companies of interest, introduced themselves, explained the project concept, and inquired if and when they might visit. Most companies welcomed the students and enthusiastically agreed to participate. A few individuals had hesitations due to privacy concerns but they were usually put at ease when students explained that the documentaries would only be used in class and would not be made public. Students generally found the interviewees to be exceptionally attentive, articulate, candid, informative, and even humorous. To express gratitude, students sent letters signed by everyone on the team to all those individuals who met with them. 
In the documentaries, students advanced observations about the companies and structures they saw, made associations to what they learned in the course, and articulated questions about what they did not yet know. Though no unoriginal content was allowed in the documentaries, students were able to include pictures provided to them to show phases of construction they were unable to see themselves.

To avoid excessive travel, students attempted to choose subjects with proximity to campus, and some teams were fortuitously able to stay on campus since construction of massive new residence halls and more than $\$ 120$ million of upgrades to the football stadium and athletic facilities were in progress. But the rural location of Mississippi State University made some lengthy expeditions unavoidable, and sometimes students traveled up to three hours to reach construction locations. If company locations were too distant to visit, students would simply conduct interviews via phone and add the information to the documentaries by various means.

Students were able to reserve equipment on campus from both the department and library. Equipment made available to students included camcorders, microphone attachments, and tripods. Students also used smartphones. When interviews were accomplished outdoors on windy days and inside noisy plants, voices were sometimes less perceptible, so students simply added subtitles to the documentaries in these instances. Apple iMovie was the software of choice to most students to edit documentaries and add voice, text, and music. Most students found this program easy to learn, almost intuitive.

Students established private accounts on YouTube to archive the documentaries and play them in class. Students gave marks to each documentary to assess both content and style. In these steel structures courses, the best documentary won the "Steely" award. The documentary constituted $20 \%$ of the students' grade.

Additionally, several questions about the documentaries were put on the final exam. Students had access to the transcripts of the documentaries to study. Transcripts typically contained 1,200 words, with as few as 600 words and as many as 2,000 words.

Two class periods were allocated to show the documentaries, with eight teams in these courses and each documentary being about ten minutes in length. More than a month in advance, roughly twenty minutes of class time was necessary to assign students the project and discuss instructions. Students said they spent anywhere from twenty to fifty hours on the project which in some instances included travel. Instructors might spend several hours to learn the basics of Apple iMovie or like software if they want to give students a brief demonstration ahead of the project. 


\section{Likes and Dislikes}

On a survey, students were asked to comment about what they liked about the documentary project. Most students enjoyed the unusual challenge, the opportunity to research a topic of choice, and the chance to be creative. Students were apparently more than ready to trek through construction sites with "boots in the mud" and go places in structures that are not open to the public. It was motivational, several students said, to see civil engineering practice in the real world. Students were delighted to meet company executives and professionals, though some students were initially shy. Many students thought the project complemented what they learned in the lectures, and they enjoyed the chance to work on a team towards a common goal with peers and new friends. Seemingly everyone was proud to show the movies they had made to the rest of the class.

On the same survey, students were asked to comment about what they disliked about the documentary project. Some students remarked that the time spent to learn how to use the equipment and software was wasteful because they will probably not use those skills on future jobs. Of the whole effort, some students said too much time was spent on movie edits and not enough time on steel structures, the course subject. Not too surprisingly, some students also found teamwork to be troublesome when they had to work around teammates' schedules and deal with teammates who did not readily contribute equally to the task. The autonomy and uncertainly of the project made a few students uneasy, and they said the project was more stressful than a learning process should be.

\section{Interest and Educational Value}

Students were asked two questions on the survey to assess interest and educational value in various project options.

- What kind of project would most interest you?

- What kind of project would help you learn the most about steel structures?

To each of the questions above, students were instructed to mark only one of the choices below.

- Traditional report and presentation

- Design of an actual steel structure

- Documentary

- None, just more lectures

The survey was administered to students on the last day of class and the responses were provided anonymously. A total of 68 of the 69 students responded to the survey.

Students' interest in various project options is portrayed in Figure 1. Some $44 \%$ of students said design of an actual steel structure would most interest them, and $40 \%$ of students said a documentary was of most interest. A traditional report and presentation received the least interest, even less than additional lectures. 


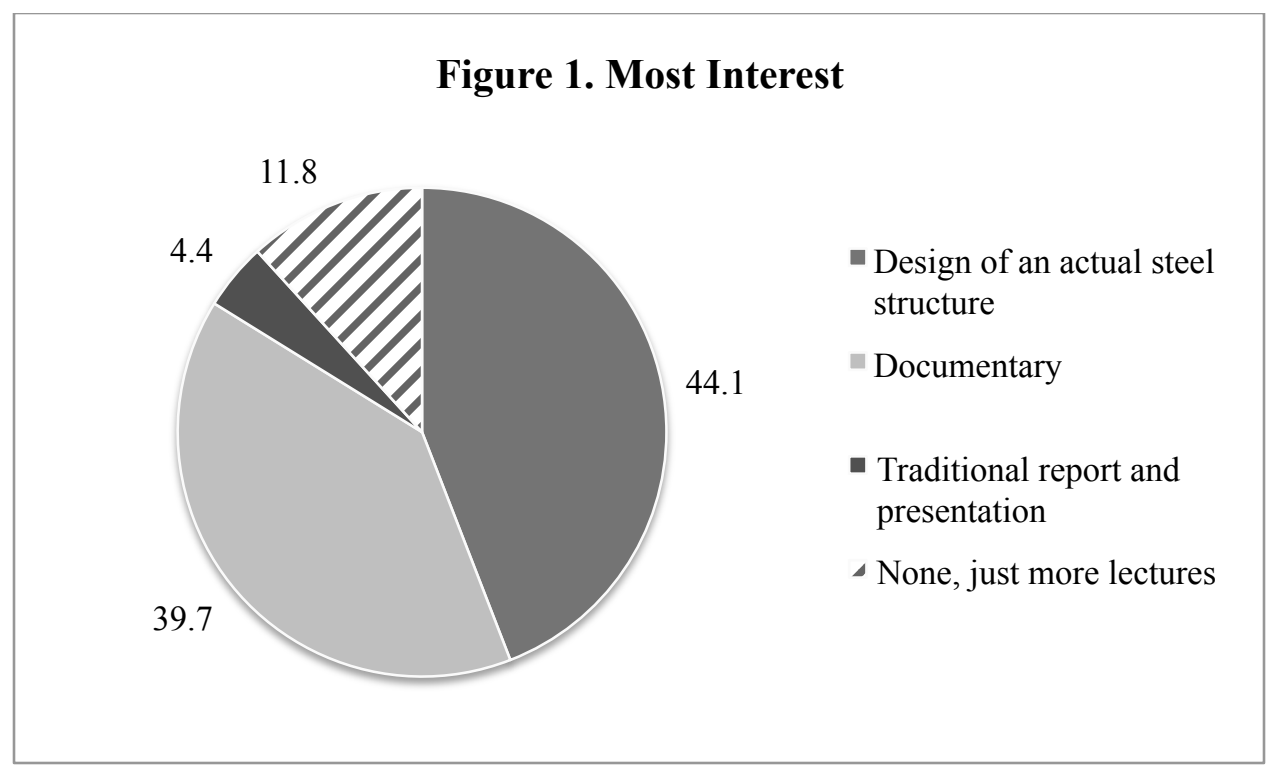

What students thought about the educational value of various project options is portrayed in Figure 2. Here students were even more emphatic about design of an actual steel structure as $59 \%$ of students said this had the most educational value. Some $22 \%$ of students said they would learn the most from a documentary project. The fewest students said they would learn the most from more lectures.

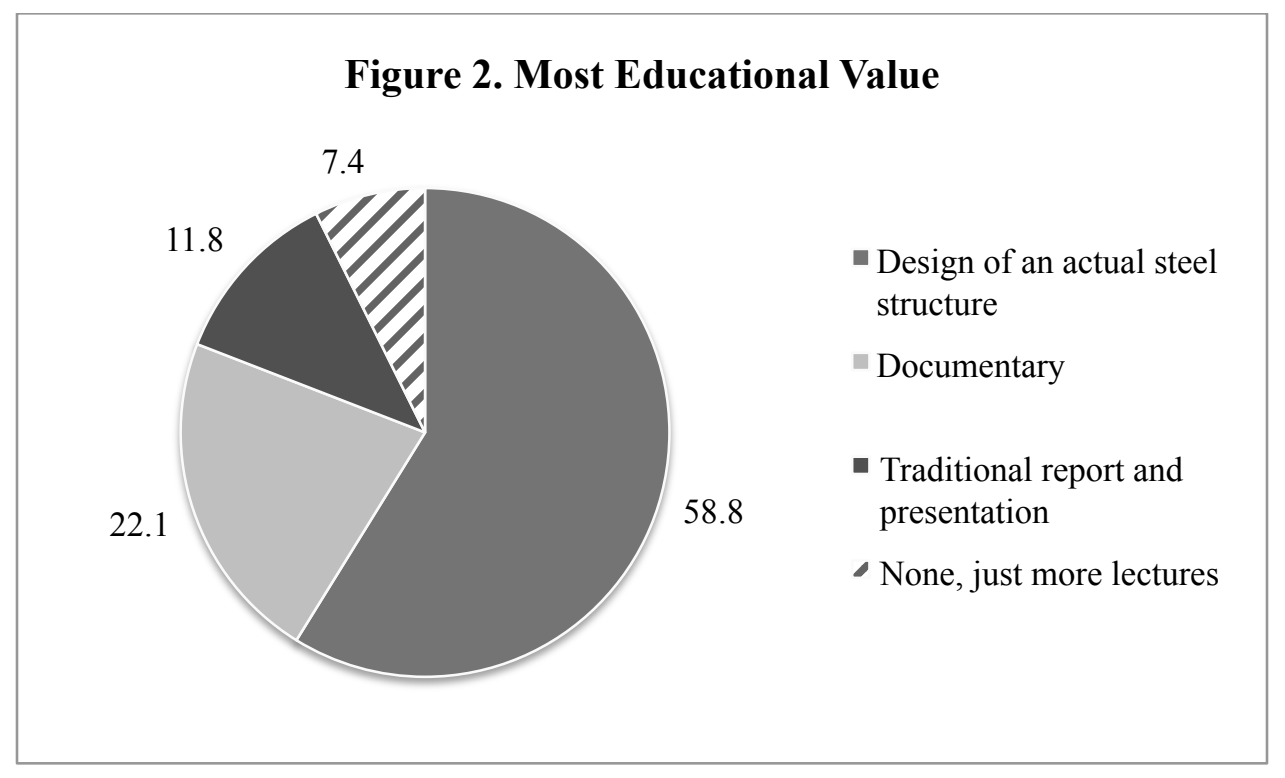

The students' preference toward design is certainly in tune with the curriculum, and a capstone course full of design experiences awaited the students in these steel structures courses. An additional opportunity to practice design is the annual AISC/ASCE National Steel Bridge Competition that generates much enthusiasm on campus.

Time limitations usually allow only one project in any course, so faculty must decide where students need the most improvement and what activities will challenge students. 
The documentary project clearly pushed students out of comfort zones and put more emphasis on communication skills than strict computational ability. To leave campus and meet new people was understandably a cause of much stress. Sometimes the true value of an experience becomes more apparent to students in the future when they face life's challenges.

\section{Conclusions}

A documentary project is very different than most and requires students to make a foray into the real world, which is a scary experience to some. Students learn a multitude of aspects about the course subject to complement the lecture material. They also learn how to interact professionally, how to work as a team, and how to collect and condense information to tell a story. The focus on communication skills is very relevant to civil engineering practice in modern times. $^{2,4}$

Additionally, this project gave students an easy and inconspicuous way to go into companies of interest and meet prospective employers, and gave companies an opportunity to renew connections with the university and meet potential new employees.

Although a plurality of students in these courses chose design of an actual steel structure highest in terms of both interest and educational value, a documentary project will push students out of comfort zones and challenge them in new ways. With applicability to almost any undergraduate civil engineering course, and fairly inexpensive to implement, an unconventional project like this might be worth the risk.

\section{Bibliography}

${ }^{\mathbf{1}}$ Richtel, M., “Technology Changing How Students Learn, Teachers Say,” The New York Times, 11/1/2012

${ }^{2}$ Pitts, D. C., Elton, D. J., and Hanson, J. L., "Use of Student Created Videos to Enhance Undergraduate Learning," Geo Frontiers Congress, ASCE, 3/2011

${ }^{3}$ Illman, D. L., "Reaching a Larger Audience," Prism, ASEE, 2/2012

${ }^{4}$ Grose, T. K., "Wow the Audience," Prism, ASEE, 12/2012 